Research Paper

\title{
Distinct roles of cortical and pallidal $\beta$ and $\gamma$ frequencies in hemiparkinsonian and dyskinetic rats
}

\author{
Agnese Salvadè ${ }^{\mathrm{a}, 1}$, Vincenza D'Angelo ${ }^{\mathrm{b}, 1}$, Giuseppe Di Giovanni ${ }^{\mathrm{c}}$, Gerd Tinkhauser ${ }^{\mathrm{d}}$, Giuseppe Sancesario ${ }^{\mathrm{b}}$, \\ Claudio Städler ${ }^{\mathrm{a}}$, Jens C. Möller ${ }^{\mathrm{a}, \mathrm{e}}$, Alessandro Stefani b,f ${ }^{\text {, }}$, Alain Kaelin-Lang ${ }^{\mathrm{a}}$, Salvatore Galati ${ }^{\mathrm{a}, *}$ \\ a Laboratory for Biomedical Neuroscience (LBN), Neurocenter of Southern Switzerland, Lugano, Switzerland \\ b Department of Neurology, University of Rome "Tor Vergata", Italy \\ c Department of Physiology and Biochemistry, University of Malta, Malta \\ d Department of Neurology, University of Bern, Switzerland \\ e Parkinson Center, Center for Neurological Rehabilitation, Zihlschlacht, Switzerland \\ ${ }^{\mathrm{f}}$ I.R.C.C.S. Fondazione S. Lucia, Rome, Italy
}

\section{A R T I C L E I N F O}

\section{Article history:}

Received 24 April 2015

Received in revised form 21 September 2015

Accepted 10 November 2015

Available online 10 November 2015

\section{Keywords:}

Beta band oscillation

Parkinson's disease

Rat animal model

Local field potentials

Recordings in freely moving animals

\begin{abstract}
A B S T R A C T
Enhanced $\beta$ band ( $\beta B$ ) activity, which is suppressed by levodopa (LD) treatment, has been demonstrated within the basal ganglia (BG) of Parkinson's disease (PD) patients. However, some data suggest that Parkinsonian symptoms are not directly related to this brain frequency and therefore, its causative role remains questionable. A less explored phenomenon is the link between the $\gamma$ band $(\gamma \mathrm{B})$ and PD phenomenology. Here, we monitored the development of the oscillatory activity during chronic LD depletion and LD treatment in Parkinsonian and levodopa-induced dyskinesia (LID) in rats. We found a significant and bilateral power increase in the high $\beta B$ frequencies (20-30 Hz) within the first 10 days after 6-hydroxydopamine (6-OHDA) lesion, which was in accordance with a significant depletion of dopaminergic fibers in the striatum. We also observed a clear-cut $\gamma B$ increase during LD treatment. The development of LID was characterized by a slight increase in the cumulative power of $\beta B$ accompanied by a large augmentation in the $\gamma \mathrm{B}$ frequency $(60-80 \mathrm{~Hz})$. This latter effect reached a plateau in the frontal cortex bilaterally and the left globus pallidus after the second week of LD treatment. Our data suggest that the $\beta B$ parallels the emergence of Parkinsonian signs and can be taken as a predictive sign of DA depletion, matching TH-staining reduction. On the other hand, the $\gamma \mathrm{B}$ is strictly correlated to the development of LID. LD treatment had an opposite effect on $\beta B$ and $\gamma B$, respectively.
\end{abstract}

(C) 2016 Elsevier Inc. All rights reserved.

\section{Introduction}

Loss of dopaminergic innervation of the striatum leads to excessive synchronized oscillatory firing within the basal ganglia (BG) circuitry. This oscillatory behavior occurs mainly in the beta band ( $\beta B)$ frequency, and it has been reported in both Parkinson's disease (PD) patients and PD animal models (Steigerwald et al., 2008; Eusebio and Brown, 2009). The relation between $\beta B$ oscillation and Parkinsonian symptoms has been identified in the cortex and BG of PD patients by local field potential (LFP) recordings. Further evidence from Parkinsonian animal models shows that these frequencies are clearly detected in the cortex during the transition from slow wave to a desynchronized pattern activity (Sharott et al., 2005; Mallet et al., 2008). Moreover, LFP recordings from $\mathrm{PD}$ patients without medication revealed prominent oscillations between $8 \mathrm{~Hz}$ and $30 \mathrm{~Hz}$, which were suggested to be the BG $\beta B$, and

\footnotetext{
* Corresponding author at: Laboratory for Biomedical Neuroscience (LBN), Neurocente of Southern Switzerland, Via Tesserete 46, 6903 Lugano, Switzerland.

E-mail address: salvatore.galati@eoc.ch (S. Galati).

1 These authors have contributed equally.
}

have resulted to be broader than the conventional $\beta$ electroencephalographic activity (Brown, 2006). The $\beta B$ may be divided in two subranges of frequencies, namely low $\beta B(\sim 10-20 \mathrm{~Hz})$ and high $\beta B(\sim 20-$ $30 \mathrm{~Hz}$ ) with presumed different functional implications (Priori et al., 2004; Avila et al., 2010). Gamma band ( $\gamma$ B) also plays a key role in movement execution with an opposite functional significance to that of the $\beta B$. $\gamma \mathrm{B}$ is classically in a range of between 35 and $90 \mathrm{~Hz}$ (Engel and Fries, 2010), and it has become known as prokinetic oscillation, as it is implicated in the initiation of movement (Brown, 2003). In contrast, $\beta B$ occurs in the maintenance of the current state. Furthermore, $\gamma \mathrm{B}$ was recently negatively correlated to bradykinesia (Sharott et al., 2014), corroborating the previously described positive correlation between $\gamma \mathrm{B}$ and improvement following dopaminergic treatment (Litvak et al., 2012).

Moreover, a direct causative relation between $\beta B$ and PD has been inferred by the subtle clinical worsening of akinesia obtained by stimulating the sub-thalamic nucleus (STN) with the $\beta B$ frequency (Timmermann et al., 2004; Eusebio et al., 2007). Nevertheless, a study performed in monkeys chronically intoxicated with 1-methyl 4phanyl 1,2,3,6-Tetrahydropyridine (MPTP) showed that the appearance 
of Parkinsonian symptoms is not dependent on $\beta B$ oscillation (Leblois et al., 2007). In agreement, results from a computational model demonstrated that moderate dopamine (DA) depletion is sufficient to provoke Parkinsonism, but only a severe DA reduction leads to the emergence of $\beta B$ frequencies (Leblois et al., 2007). The dissociation between $\beta B$ and clinical symptoms is also evident in studies performed on PD patients where it is not correlated with clear changes in motor performance, rather, it is correlated to clinical amelioration after LD challenge (Weinberger et al., 2006). Of note, $\beta B$ recorded in STN of PD patients correlated with limb rigidity, but there was no clear association with the main symptom of Parkinsonian syndrome, i.e., the bradykinesia (Sharott et al., 2014). Surprisingly, bradykinesia was inversely correlated with the neuronal oscillation in the $\gamma \mathrm{B}$ range (Sharott et al., 2014). While pharmacological STN inhibition is able to give clinical benefit without suppressing $\beta B$ (Levy et al., 2001), $\beta$ power recorded within the STN is suppressed prior to movement initiation with a clear correlation with task demands. Furthermore, recent investigations performed in PD patients subjected to functional surgery have revealed a new perspective on the fine balance between $\beta$ and $\gamma$ oscillations during a simple stop signal task (Alegre et al., 2013).

Based on these results, the aim of the present study was to monitor these two bands in the frontal cortex and the globus pallidus (GP) in 6hydroxydopamine (6-OHDA)-Parkinsonian freely moving rats. We focused our study on the GP because in a normal condition inverselyrelated to the STN, its activity is relatively unaffected by the cortical activity (Galati et al., 2009). Moreover, the dynamic changes of $\beta B$ and $\gamma \mathrm{B}$ were correlated to behavioral modification in Parkinsonian rat motor performance and, furthermore, to the development of LD-induced dyskinesia (LID).

\section{Methods}

\subsection{Animals at $L B N$ : experimental design}

24 adult male Sprague-Dawley rats (Harlan Italy, Udine), weighing 170-200 $\mathrm{g}$ at the beginning of experiment, were randomly housed in the animal rooms at LBN. They were placed under a 24-h cycle consisting of $12 \mathrm{~h}$ of light and $12 \mathrm{~h}$ of darkness with free access to food and water. The room temperature, humidity, and air exchange were automatically controlled. All animal procedures were approved by the Animal Research Committee and the Veterinary Office of the Canton of Ticino, Switzerland. Twenty-three rats received a unilateral DAdenervating lesion by stereotactic injection of 6-OHDA toxin into the left medial forebrain bundle, as described below. One rat received a sham surgery lesion. During the same surgical procedure rats were also implanted with electrodes for electrophysiological recordings. Five 6-OHDA-lesioned rats presented technical problems (bad quality of LFP recordings or electrode removal) and were thus excluded. Seventeen rats were successfully lesioned (Apo test positive), whereas, one rat did not display unilateral dopaminergic lesion (APO test negative) and was excluded from data analysis. Five 6-OHDA-lesioned rats were sacrificed after the APO test, whereas, 11 rats followed the study with LD treatment and 1 rat followed the study without LD. 4 weeks after APO test, 8 rats (6-OHDA-lesioned and LD treated) were selected for $\mathrm{LD}$ test. The study design and the number of animals are depicted in Fig. 1A.

\subsection{Animals at the Department of Neurology, University of Rome}

Additional histological experiments were conducted in the laboratory of University of Rome Tor Vergata in compliance with Italian laws on animal experimentation (D.L. 116/1992) and with the National Institutes of Health Guide for the Care and Use of Laboratory Animals. This sub-set of experiments was carried out on additional 12 adult male rats, weighing 250-300 g, plus 7 out of 24 rats treated at the LBN.

\subsection{Unilateral 6-OHDA lesion model of PD}

Unilateral (left hemisphere) DA denervation was performed according to a standard protocol (Schwarting and Huston, 1996; Galati et al., 2008). Briefly, rats were anesthetized with $1.5-2.5 \%$ isoflurane in oxygen and mounted on a stereotaxic instrument (Stoelting Co., Wheat Lane, Wood Dale, IL, USA). Body temperature was maintained at $37^{\circ}$ $38{ }^{\circ} \mathrm{C}$ with a heating pad (Stoelting Co., Wheat Lane, Wood Dale, IL, USA) placed beneath the animal. After a sub-cutaneous injection of the local anesthetic lidocaine, a midline scalp incision was made and a hole $(\varnothing \sim 1.0 \mathrm{~mm})$ was drilled in the skull on the left side. The neurotoxin (30 mM solution of $6-$ OHDA containing $0.03 \%$ of ascorbic acid) was injected into the medial forebrain bundle (MFB; coordinates: $4.0 \mathrm{~mm}$ posterior of the bregma, $1.3 \mathrm{~mm}$ laterally of the midline and $7.0 \mathrm{~mm}$ beneath the cortical surface). Injections of $3 \mu \mathrm{l}$ of 6-OHDA were administered through a 30-gauge cannula connected to a $10 \mu \mathrm{l}$ Hamilton syringe over a period of $3 \mathrm{~min}$. The injection of the neurotoxin was preceded by a bolus of desipramine $(25 \mathrm{mg} / \mathrm{kg}$, i.p.) in order to minimize the uptake of 6-OHDA by noradrenergic neurons. After the 6-OHDA lesion, during the same surgical procedures, electrodes for electrophysiological recordings were implanted (see in Methods, sub-section Electrophysiological recordings).

Twenty days later, an apomorphine (APO)-induced rotation test $(0.05 \mathrm{mg} / \mathrm{kg}$, s.c.) was performed in order to assess the severity of nigral lesions (Galati et al., 2008; Hudson et al., 1993). Animals performing at least 100 rotations opposite to the lesion site within 20 min of the APO treatment (Cenci et al., 1998) were considered successfully lesioned and included in the study.

\subsection{Elevated body swing test}

The elevated body swing test (EBST) was used to estimate the effects of unilateral 6-OHDA lesions on the nigrostriatal pathway (Borlongan and Sanberg, 1995). 5 out of the 12 recorded 6-OHDA-lesioned rats were randomly selected for EBST between $\mathrm{d} 2$ and $\mathrm{d} 11$. These animals were placed consecutively into a Plexiglas box and were allowed to get habituated for $2 \mathrm{~min}$. Each animal was held approximately at the base of its tail and then elevated to $2.5 \mathrm{~cm}$ above the surface on which it had rested. The animal was held on the vertical axis and a swing was recorded whenever the animal moved its head out of the vertical axis to either side. Before attempting another swing, the animal had to return to the vertical position for the next swing to be counted. The total number of swings made to the right side was divided by the total number of swings made to both sides to get the percentage of contralateral, right swings. The criterion for biased swing behavior was set at $70 \%$ or higher (Borlongan and Sanberg, 1995).

\subsection{Induction of dyskinesia by chronic levodopa treatment}

6-OHDA-treated animals were submitted to LD treatment (LD $100 \mathrm{mg}$ plus benserazide $25 \mathrm{mg}$, Madopar LIQ ${ }^{\circledR} 125 \mathrm{mg}$ dissolved onto $200 \mathrm{ml}$ of drinking water). We adopted an oral schema of administration in order to permit a chronic exposure without interfering with the electrophysiological recordings of LFPs. In order to confirm if the LID induction was successfully achieved, 4 weeks later we performed a sub-cutaneous LD test on 8 rats $(15 \mathrm{mg} / \mathrm{kg} \mathrm{LD}$ plus $8 \mathrm{mg} / \mathrm{kg}$ benserazide) in order to characterize the animals showing LID. The behavioral assessment was performed by observing the animals in their individual cages, as already described (Cenci et al., 1998). Abnormal movements were scored according to a scale of 0 to 4 for each of the following four categories: 1) limb dyskinesia, 2) axial dystonia, 3 ) orolingual movements and 4) rotational/locomotor behavior. "0" was assigned in the case of absence of abnormal movements; "1" indicated the presence of dyskinesia occurring for less than half the observational period; "2" was attributed when dyskinetic movements occurred for more than half the observational period; " 3 " indicated a condition in 


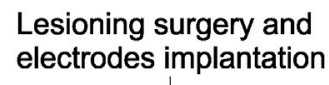

$1 \mathrm{w}$

$2 w \quad 3 w \quad 4 w$

Levodopa treatment

\begin{tabular}{|c|c|c|c|}
\hline $\begin{array}{c}\text { EEG electrodes } \\
\text { implantation }\end{array}$ & $\begin{array}{l}\text { Rats recorded } \\
\text { for the } 1^{\text {st }} 10 \mathrm{~d}\end{array}$ & $\begin{array}{l}\text { Rats recorded } \\
\text { for the } 2^{\text {nd }} 10 \mathrm{~d}\end{array}$ & $\begin{array}{l}\text { Rats recorded during } \\
\text { levodopa treatment }\end{array}$ \\
\hline DYS-
\end{tabular}

B

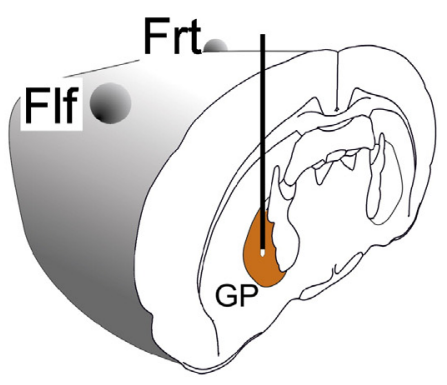

SNC

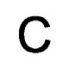

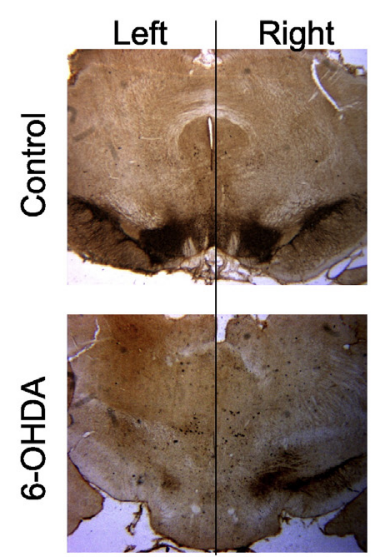

Striatum

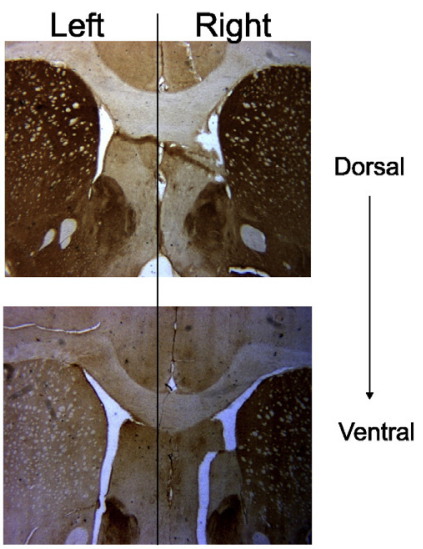

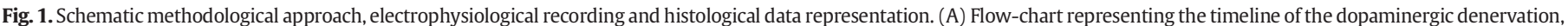

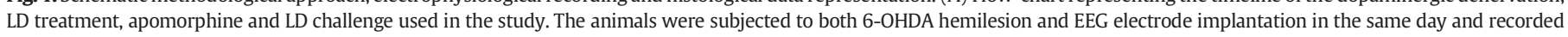

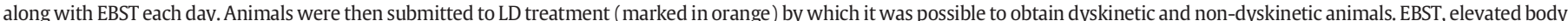

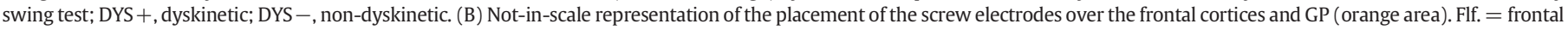

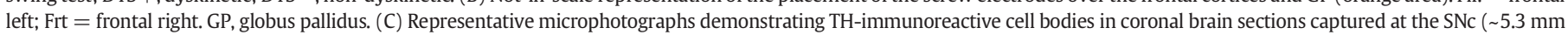

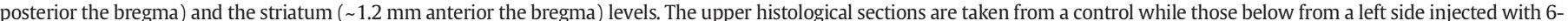
OHDA animal. SNc, substantia nigra pars compacta. (For interpretation of the references to color in this figure legend, the reader is referred to the web version of this article.)

which constant dyskinesia was only briefly interrupted; and "4" refers to constant, uninterrupted dyskinesia. The behavioral assessment yielded a subdivision of chronically LD treated rats into dyskinetic and non-dyskinetic sub-groups.

\subsection{Electrophysiological recordings}

LFPs were simultaneously recorded from the ipsilateral GP and both frontal cortices (electroencephalogram; EEG) in awake, freely moving animals (Fig. 1B).

Electrodes for electrophysiological recordings were implanted immediately after the 6-OHDA lesion in order to start daily recordings, starting the day of lesion. Two gold $1 \mathrm{~mm}$ diameter screw electrodes (gold plated screws, conical cross S1, Svenska Dentorama AB) were implanted bilaterally in the frontal cortex (coordinates: $2 \mathrm{~mm}$ anterior of the bregma, $3 \mathrm{~mm}$ laterally to the midline in the left and right frontal skull (Paxinos and Franklin, 2004) under isoflurane anesthesia and after $6-O H D A$ injection. Also, a wire recording electrode (22 $\mu \mathrm{m}$, Stablohm 650; California Fine Wire, Grover Beach, California) was implanted into the GP (coordinates: $-1.0 \mathrm{~mm}$ posterior of the bregma, $3.0 \mathrm{~mm}$ lateral to the midline and $6.0 \mathrm{~mm}$ ventral to the cortical surface (Paxinos and Franklin, 2004)). One reference epidural screw electrode was placed over the right cerebellar hemisphere. All electrodes were connected to a miniature custom-built socket (360-6746 RS Components, Mörfelden-Walldorf, Germany), which was cemented to the skull with stainless-steel anchor screws (Plastics One) and paladur dental acrylic cement (Dental Pro SA, Manno, Switzerland). LFP recordings were obtained for 10 min during rest periods at the same time each day (10.00 a.m.). During the recordings, the animals were kept in a quiet condition to avoid any alerting stimuli except during the APO test where the animals had a rotatory patterned behavior..

\subsection{Data acquisition and analysis of electrophysiological recordings}

We performed the electrophysiological recordings every day, starting the day after the surgery (T0). The signal was digitalized online with a Spike2 interface and acquisition software (version 6.1; Cambridge Electronic Design Ltd., Cambridge, UK) with a sampling rate of $1 \mathrm{kHz}$. Epochs of $100 \mathrm{~s}$, which were free of artifacts and representative of the overall recording, were selected from $10 \mathrm{~min}$ of recordings. We applied an off-line band-pass filter between $8 \mathrm{~Hz}$ and $100 \mathrm{~Hz}$ and then smoothed the epochs to $250 \mathrm{~Hz}$. We calculated the total power values using a dedicated Spike2 script (SUDSA 22) in the $20-35 \mathrm{~Hz}$ (high $\beta$ ) and $60-80 \mathrm{~Hz}(\gamma)$ frequency range.

\subsection{Tyrosine hydroxylase immunohistochemistry}

After completing the recordings, rats were anesthetized with 3\% isoflurane in oxygen and perfused intracardially with $200 \mathrm{ml}$ cold saline followed by $200 \mathrm{ml} 4 \%$ paraformaldehyde and heparine $(10 \mathrm{U} / \mathrm{ml})$ in a phosphate buffer solution. The brains were removed immediately and post-fixed in the same fixative solution overnight at $4{ }^{\circ} \mathrm{C}$. Coronal brain $40-\mu \mathrm{m}$-thick sections were cut with an Oxford vibratome across the entire rostrocaudal extent of the striatum and midbrain and were 
Table 1

Animal used in this study.

\begin{tabular}{ll} 
Total rats included in the study & $\mathrm{n}=36$ \\
Rats treated at LBN (CH) & $\mathrm{n}=24$ \\
Rats processed for histology in Rome & $\mathrm{n}=12$ \\
EBST test & $\mathrm{n}=5$ \\
APO test & $\mathrm{n}=18$ \\
APO+ & $\mathrm{n}=17$ \\
APO- & $\mathrm{n}=1$ \\
Recording data & $\mathrm{n}=18$ \\
Sham-lesioned, recorded pre- and post-apo test & $\mathrm{n}=1$ \\
6-OHDA-lesioned, recorded pre- and post-apo test & $\mathrm{n}=1$ \\
6-OHDA-lesioned, LD treated, recorded pre- and post-apo test & $\mathrm{n}=6$ \\
6-OHDA-lesioned, recorded only pre-apo test & $\mathrm{n}=5$ \\
6-OHDA-lesioned, LD treated, recorded only post-apo test & $\mathrm{n}=5$ \\
Rats observed for LID & $\mathrm{n}=8$ \\
Dyskinetic rats & $\mathrm{n}=5$ \\
Non-dyskinetic rats & $\mathrm{n}=3$ \\
Histology & $\mathrm{n}=19$ \\
Rome rats & $\mathrm{n}=12$ \\
LBN rats & $\mathrm{n}=7$ \\
\hline
\end{tabular}

collected and stored at $4{ }^{\circ} \mathrm{C}$ in $0.1 \mathrm{M}$ phosphate buffer that contained $0.02 \%$ sodiumazide. We established the degree of dopaminergic damage within the substantia nigra compacta (SNc) and the ipsilateral striatum by tyrosine hydroxylase (TH) immunostaining (Fig. 1C; Galati et al., 2010). Stained sections were also used to verify the position of the electrode within the GP. Free-floating sections were washed three times with Tris-buffered saline, $\mathrm{pH} 7.4$, and endogenous peroxidase activity was inactivated by Tris-buffered saline containing $2 \% \mathrm{H}_{2} \mathrm{O}_{2}$. The sections were rinsed with Tris-buffered saline ( $0.1 \%$ Triton X-100 and $2 \%$ normal goat serum) and incubated with $2 \%$ normal goat serum followed by overnight incubation at $4{ }^{\circ} \mathrm{C}$ with mouse anti-TH primary antibodies (1:1000; Immunostar Inc., Hudson, WI, USA). Primary antibodies were detected using a biotinylated secondary antibody (Vector Laboratories, Vectastain ABC Kit, Burlingame, CA, USA) and an avidin horseradish peroxidase-diaminobenzidine- $\mathrm{H}_{2} \mathrm{O}_{2}$ chromogen system (Sigma Fast; Sigma-Aldrich). After the diaminobenzidine reaction, sections were rinsed with Tris-buffered saline, mounted on gelatin-coated slides, dehydrated, and coverslipped with Permount for light microscope examination. The sections were observed and photographed with a light microscope (Olympus BX51, Tokyo, Japan) equipped with an automatic microcamera (Leica DC 300F, Q550 IW Soft, Wetzlar, Germany).

\subsection{Image analysis for striatal fiber density measurement}

After TH staining, the images of striatal sections were acquired with a camera (Sony DXC, Sony, Belgium) that was connected to the microscope and a computer. Density was measured using a specific software, the Gray Scale Program included in IAS 2000 (Delta Sistemi, Milan, Italy); this program, in principle, allows the transformation of the immunoreactive optical density per unit area into a scale (from 0 to 255; higher values indicate "light-permissive" fields under light microscopy, in other words, absence of immunoreactivity (hence, more extended lesioning). Notably, this analysis, also recently validated in transgenic dystonic mice (D'Angelo et al., 2015), was operated by an expert blind to the treatment conditions. In detail, five coronal serial sections in each hemisphere, at the same level for each animal, were selected for density measurement (comparing right versus left - lesioned - sites). (Sancesario et al., 2004; Galati et al., 2009).

\subsection{Statistical analysis}

Statistical analysis was performed using statistical software (IBM SPSS). The power of the two analyzed frequency bands were tested for normal distribution by the Kolmogorov-Smirnov test. In the first 10 days, we defined significant fluctuations as a change in power magnitude that was greater than the mean change \pm 2 standard deviations (SD).

We tested the power of the frequency bands for the factor "time" in the subsequent period after the injection of 6-OHDA (T0, first 10 days, second 10 days and APO test) and during LD treatment ( $1 \mathrm{~W}$, first week; $2 \mathrm{~W}$ second week; $3 \mathrm{~W}$, third week; $4 \mathrm{~W}$, fourth week) by repeated-ANOVA analysis (RM-ANOVA) with a Greenhouse-Geisser correction in al rats. The same analysis was chosen for the behavioral analysis. In case of significance, the post hoc test was corrected accordingly, using Bonferroni correction.

A Pearson correlation was used to correlate behavioral data (EBST test performed on the following days: d2, d3, d4, d5, d7, d8, d9, d10, d11) with the $\beta B$ power.

Finally, we used a parametric t-test analysis for comparison of the total cumulative power during LD treatment between dyskinetic and non-dyskinetic animals, between the left and right TH striatal density.

\section{Results}

The study design is depicted in Fig. 1A, and the number of animals in Table 1.

3.1. The 6-OHDA injection caused a progressive increase of high $\beta B$, matching the development of Parkinsonism and TH-staining reduction

We simultaneously recorded the LFPs of 14 animals (6-OHDA-lesioned rats $n=13$; sham-lesioned rat $n=1$ ) from the bilateral frontal cortices and the left GP during the period encompassed by the 6-OHDA injection and the APO test. One 6-OHDA-lesioned rat produced a negative result to the APO test and was excluded from data analysis. We found a similar pattern of frequency oscillatory activity in the three different brain structures of the 6-OHDA-lesioned rats (Fig. 2). A RMANOVA determined that power of the high $\beta B$ significantly changed during the days between the 6-OHDA lesion (T0) and the APO test (T20) in the three structures (RM-ANOVA, $\mathrm{n}=12$, frontal left: $\mathrm{F}=$ 9.882, $\mathrm{P}=0.002$; frontal right $\mathrm{F}=32.703, \mathrm{P}=0.000 ; \mathrm{GP}: \mathrm{F}=13.639$, $\mathrm{P}=0.012$; Fig. 2).

Post hoc analysis using the Bonferroni test correction revealed that high $\beta B$ increased in the first 10 days after the 6-OHDA injection in the frontal left, the frontal right, and the left GP (T0 vs 1 st 10 days; $\mathrm{P}=0.006 ; \mathrm{P}=0.007 ; \mathrm{P}=0.011$ respectively; Fig. 2 ). The comparison of high $\beta B$ power between the 1 st 10 days and 2 nd 10 days showed a further, unexpected increase of the high $\beta B$ significance only in the frontal right cortex ( 1 st 10 days vs 2 nd 10 days; $P=0.007$; Fig. 2 ). In the sham-lesioned rat, we did not observe any change (data not shown). Within the first 10 days after the 6-OHDA injection, we found a significant increase of $\beta$ power on the fifth day in both the left and right cortices and on the fourth day in the GP $(>2-\mathrm{SD})$.

As depicted in Fig. 2, we found no clear changes between the basal values of $\gamma \mathrm{B}$ during the 20-day period after the injection of 6-OHDA.

Behavioral data analysis was performed by the EBST on five randomly selected 6-OHDA-lesioned rats 8 days after DA depletion. Later, these rats tested positive for the APO test). The EBST test showed a clear side-

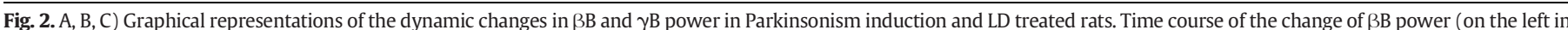

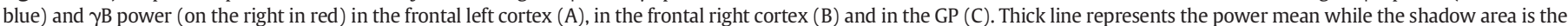

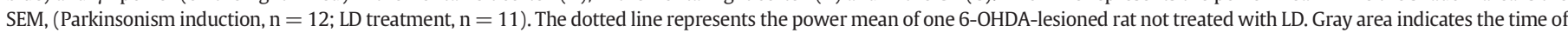

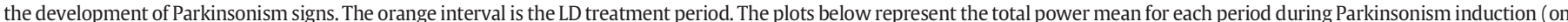

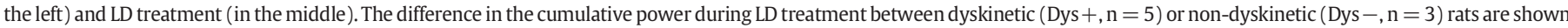

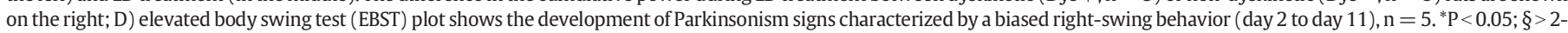
SD; APO: apomorphine; the error bar is the SEM. (For interpretation of the references to color in this figure legend, the reader is referred to the web version of this article.) 

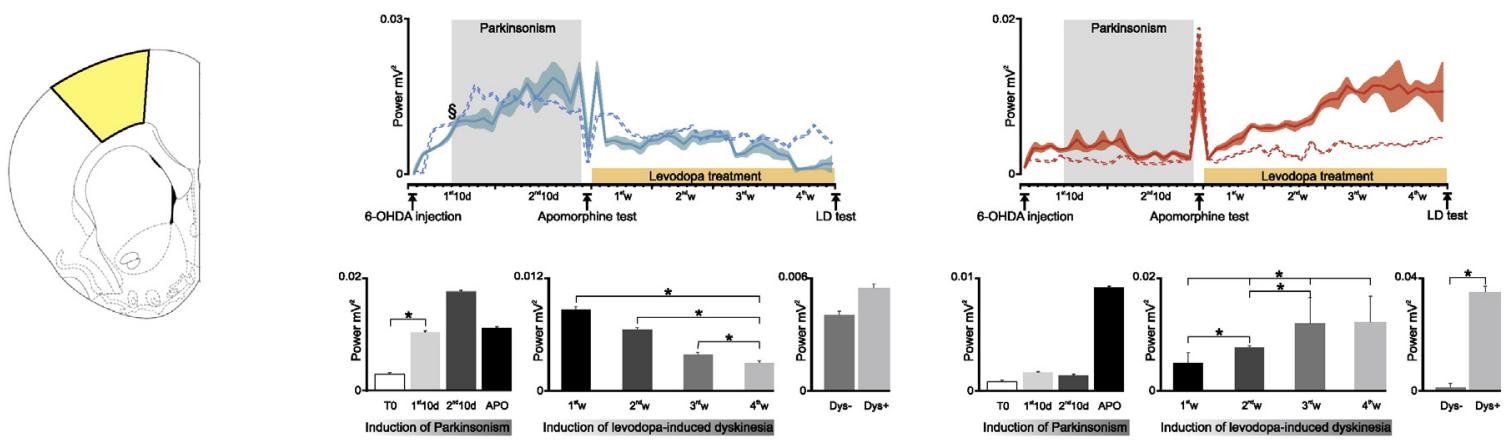

\section{B Frontal right ECoG}
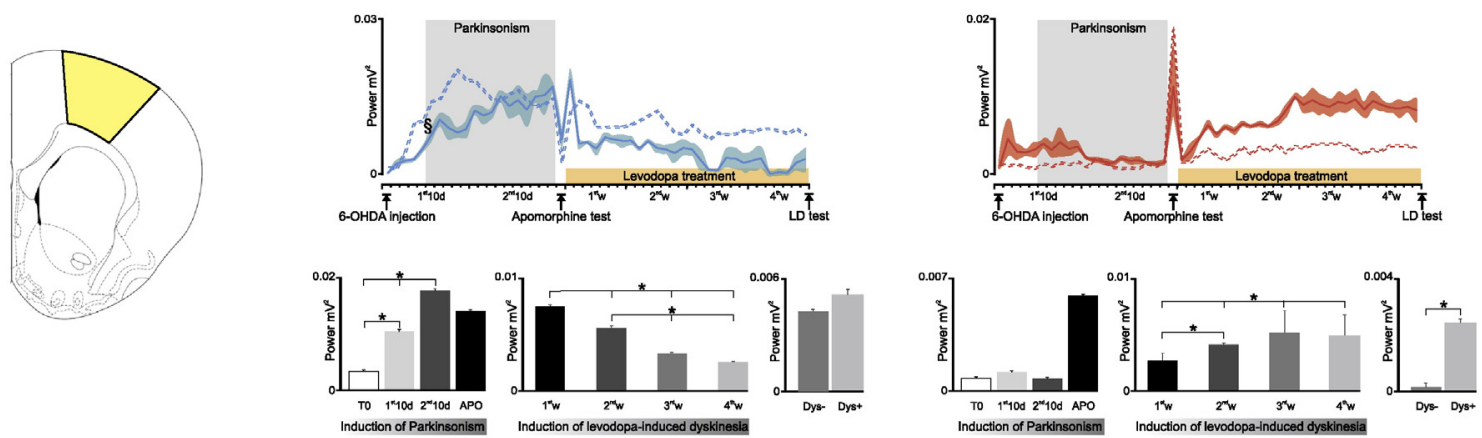

\section{Pallidal LFP}

High beta band $(20-35 \mathrm{~Hz})$

Gamma band $(60-80 \mathrm{~Hz})$
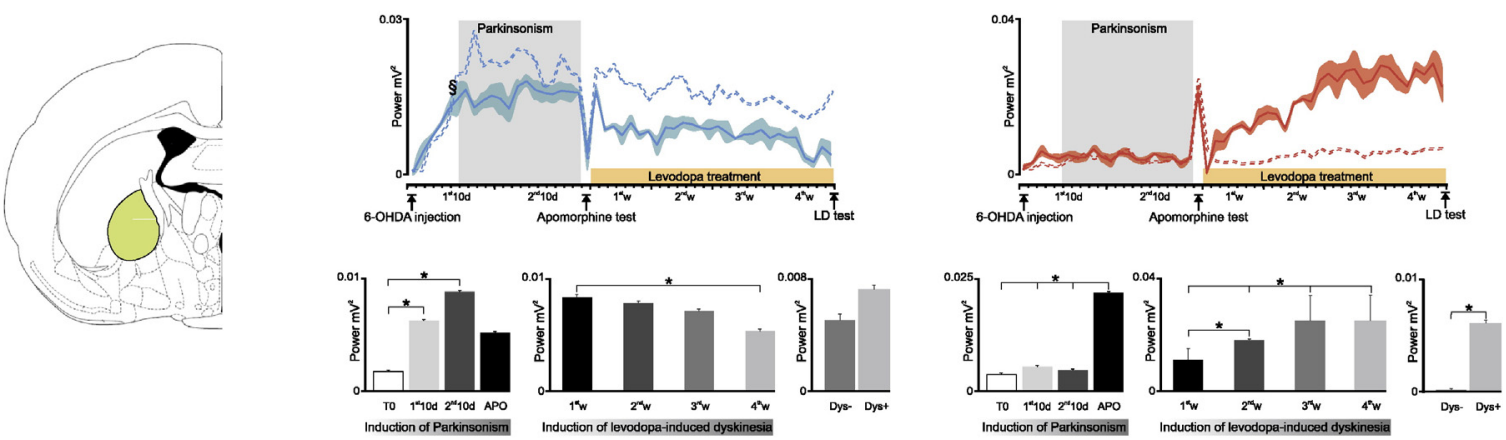

\section{Elevated Body Swing Test}

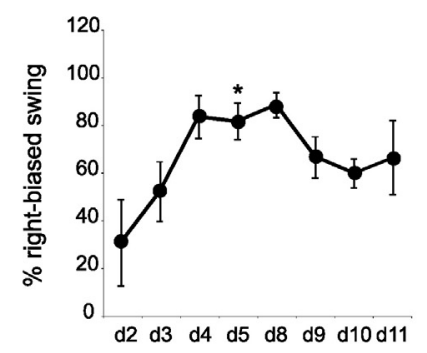


turning dominance that reached significance on the fifth day after the 6OHDA injection $(\mathrm{n}=5 ; \mathrm{F}=4.629, \mathrm{P}=0.035$; $\mathrm{d} 4 \mathrm{vs} \mathrm{d} 5, \mathrm{P}=0.028$; Fig. 2D). A Pearson correlation between electrophysiological and behavioral data, performed on 5 rats over 8 days, demonstrated a positive correlation between $\beta$ power in the three structures and all the behavioral data collected during the first two weeks after the DA depletion (Fig. 3). In detail, we found a robust positive correlation between GP $\beta$ power and EBST (frontal left: $r=0.404, n=29, P=0.030$, Fig. $3 A$; frontal right $r=0.369, n=29, P=0.049$, Fig. 3B; GP: $r=0.565, P=0.001$; Fig. 3C).

Furthermore, the histological evaluation demonstrated an initial damage of DA fibers: the animals sacrificed within the 1 st 10 days showed a significant reduction of TH staining in the lesioned hemisphere in comparison with the contralateral ones $(\mathrm{n}=10 ; 141.9 \pm$ 5.1 vs $158.3 \pm 5.7 ; \mathrm{P}=0.05$; Fig. $4 \mathrm{C}$ ).

This difference was most pronounced in the 2 nd 10 day period $(\mathrm{n}=$ $5 ; 149.8 \pm 1.62$ vs $165.6 \pm 3.5 ; P=0.006$; Fig. $4 \mathrm{D}$ ), yet there was no statistical difference between the 1 st 10 days and the 2 nd 10 day periods.

In the control and sham groups, the difference between the two hemispheres was not significant, as expected (for the lesioned side control $\mathrm{n}=6,123.8 \pm 5.4$ vs sham $\mathrm{n}=6$ MA SONO SEZIONI DI $\mathrm{N}=1$ RAT, $136.9 \pm 2.5$ in comparison with the contralateral side, control $\mathrm{n}=5$, $120.3 \pm 2.5$ vs sham $n=6,137.5 \pm 2.5$, respectively; Fig. 4).

\subsection{APO induced a significant increase of $\gamma B$ power selectively in the GP but not in the cortex}

The APO test caused a sharp increase $\gamma \mathrm{B}$ power in both the left and right cortices (Fig. 2A, B); however, this failed to reach a statistical significance. Conversely, the RM-ANOVA found a significant change of the $\gamma \mathrm{B}$ power in the GP $(\mathrm{F}=78.742, \mathrm{P}=0.000)$. Specifically, the $\gamma \mathrm{B}$ power was augmented significantly during the APO test compared with the basal value at 10 days and 20 days after the 6-OHDA injection (T0 vs $\mathrm{APO}, \mathrm{n}=12, \mathrm{P}=0.002 ; 1$ st 10 days vs $\mathrm{APO}, \mathrm{P}=0.008$; 2nd 10 days vs $\mathrm{APO}, \mathrm{P}=0.006$; Fig. $2 \mathrm{C}$ ).

\subsection{The chronic $L D$ treatment caused a progressive decline of high $\beta B$ and increase of $\gamma B$ power}

After the APO test, eleven rats were subjected to oral LD treatment for four weeks, whereas, 1 rat did not receive it (sham-LD treated). In agreement with the results of the APO test, after the start of the LD treatment, we observed a progressive reduction of the power of $\beta B$ in both the frontal cortices and the GP ( $\mathrm{n}=11$; RM-ANOVA with a Greenhouse-Geisser correction for left cortex: $\mathrm{F}=15.289, \mathrm{P}=0.005$; right cortex: $F=32.339, P=0.001$; GP: $F=7.314, P=0.019$; Fig. 2). This reduction was slightly lower in the left frontal cortex with a substantial reduction of the high $\beta B$ power between the last week and the first three weeks (W1 vs W4, P $=0.003$; W2 vs W4, $\mathrm{P}=0.023$; W3 vs $\mathrm{W} 4, \mathrm{P}=0.025$; Fig. $2 \mathrm{~A}$ ). Unexpectedly, the high $\beta \mathrm{B}$ power decrease was most pronounced on the right, unlesioned side (W1 vs W2, P = 0.013 ; $\mathrm{W} 1$ vs $\mathrm{W} 3, \mathrm{P}=0.022$; $\mathrm{W} 1$ vs $\mathrm{W} 4, \mathrm{P}=0.004$; $\mathrm{W} 2$ vs $\mathrm{W} 4, \mathrm{P}=$ 0.008 ; Fig. 2B). A significant reduction of high $\beta B$ power was observed in the GP only between the first and the last weeks (W1 vs W4, P = 0.026; Fig. 2C).

On the contrary, the power of $\gamma \mathrm{B}$ progressively increased at an extensive rate in both the frontal cortices and the GP ( $\mathrm{n}=11$; RMANOVA with a Greenhouse-Geisser correction for left cortex: $\mathrm{F}=$ 17.586, $\mathrm{P}=0.004$; right cortex: $\mathrm{F}=26.569, \mathrm{P}=0.000 ; \mathrm{GP}: \mathrm{F}=$ $37.263, \mathrm{P}=0.000$; Fig. 2 ). In the three structures, the augmentation of the $\gamma \mathrm{B}$ power reached a plateau in the third week. In detail, in the left cortex, the $\gamma B$ increase was already significant between the first and the second weeks (W1 vs W2, P =0.000; Fig. 2A), the second and the third weeks (W2 vs W3, P = 0.010; Fig. 2A) but not between the third and the fourth weeks (W3 vs W4, P $=1.000, P>0.05$; Fig. 2A). As far as the right, unlesioned frontal cortex is concerned, we found that the power increase reached a maximum in the second week after LD treatment (W1 vs W2, $\mathrm{P}=0.000$; $\mathrm{W} 2$ vs $\mathrm{W} 3, \mathrm{P}=0.226$ not significant; $\mathrm{W} 3$ vs $W 4, P=1.000 \mathrm{P}>0.05$; Fig. $2 \mathrm{~B}$ ). In the GP, we observed a similar dynamic pattern of $\gamma B$ activity over the time course (W1 vs $W 2, P=0.000$; W2 vs W3, $\mathrm{P}=0.091 \mathrm{P}>0.05$; W3 vs $\mathrm{W} 4, \mathrm{P}=1.000 \mathrm{P}>0.05$; Fig. $2 \mathrm{C}$ ).

\subsection{The development of LID was associated with a distinctive increase of $\gamma B$ power}

Only 8 out of 11 animals completed the 4 weeks of recording during the LD treatment and were, therefore, tested with a s.c. LD challenge. Five of these animals developed LID (AIMs $=2.08 \pm 0.28$ ) while no involuntary movements were observed in 3 rats. Then we performed a sub-analysis between the animals that developed LID and compared them with those that did not show abnormal movement. We found a significant increase of cumulative $\gamma B$ power in dyskinetic animals during the fourth weeks of $\mathrm{LD}$ treatment in all the analyzed brain structures (frontal left, $\mathrm{t}(6)=4.00, \mathrm{P}=0.000$; frontal right $\mathrm{t}(6)=4.00, \mathrm{P}=0.001$; $\operatorname{GPt}(6)=4.00, \mathrm{P}=0.007$, Fig. 2). On the other hand, we did not find any significant difference in the $\beta B$ cumulative power (Fig. 2).

\section{Discussion}

In this study, we examined the effect of chronic DA depletion and dopaminergic treatment on the $\beta B$ and $\gamma \mathrm{B}$ power within the frontal cortex and the GP using LFP recordings. Despite the lateralized feature of the rat model utilized herein, the power of $\beta \mathrm{B}$ and $\gamma \mathrm{B}$ followed a similar pattern in both frontal cortices. In line with these results, it has been demonstrated that unilateral dopaminergic denervation is able to affect the unlesioned hemisphere, which is likely due to the bilateral projections from the SNc (Vorobyov and Sengpiel, 2008; Lehmkuhle et al., 2009; Morgan and Huston, 1990; Pierucci et al., 2009). In addition, a recent observation suggested the importance of inter-hemispheric coupling in the $\beta B$ range between the left and right cortices in a rat model of PD (Javor-Duray et al., 2014). However, a cortical LFP recording from the discrete motor primary cortex demonstrated that pathological cortical oscillation in Parkinsonism could be a phenomenon, involving only the lesioned hemisphere (Halje et al., 2012).

We also observed that the high $\beta B$ power was significantly augmented between the 1 st 10 days and the 2 nd 10 days only in the unlesioned, right cortex, attesting an independent mechanism underlying the emergence of electrophysiological changes at this level (Galati et al., 2008; Pierucci et al., 2009).

Apart from the cortex, we focused our study on the GP for two main reasons: (i) this nucleus is not affected, at least under normal conditions, by cortical activity and (ii) it is considered a major "hub" within the BG (Galati et al., 2009; Gittis et al., 2014). Moreover, while the STN appears to be strictly locked to the cortex, the GP is subjected to a fine modulation from the striatum, STN, and SNc (Galati et al., 2009; Gittis et al., 2014). Our understanding of the GP is undergoing a reinterpretation based on recent findings; indeed, a growing body of experimental evidence demonstrates that the GP is a heterogeneous structure with different circuits (Nambu and Llinaś, 1994; Hoover and Marshall, 1999; Bolam et al., 2000; Kita and Kita, 2001; Flandin et al., 2010; Nóbrega-Pereira et al., 2010; Benhamou et al., 2012; Mastro et al., 2014). Pallidal neurons fire tonically with a frequency range of 10 to $80 \mathrm{~Hz}$ in physiological conditions at rest in vivo, while during movement, they respond with complex temporal patterns and low correlation (DeLong et al., 1985; Jaeger et al., 1995; Nini et al., 1995; Turner and Anderson, 1997). Physiological pallidal activity is not linked to the cortex, and GP neurons usually have a high and regular firing rate that remains high during slow-wave activity (Galati et al., 2009). Recently, a novel, molecularly-defined cell type in the GP, the arkypallidal GP neuron, has been described with a lower and very irregular firing rate that is further suppressed during sleep (Mallet et al., 2012; Gittis et al., 2014). Future studies are required to clarify to what extent the robust and 

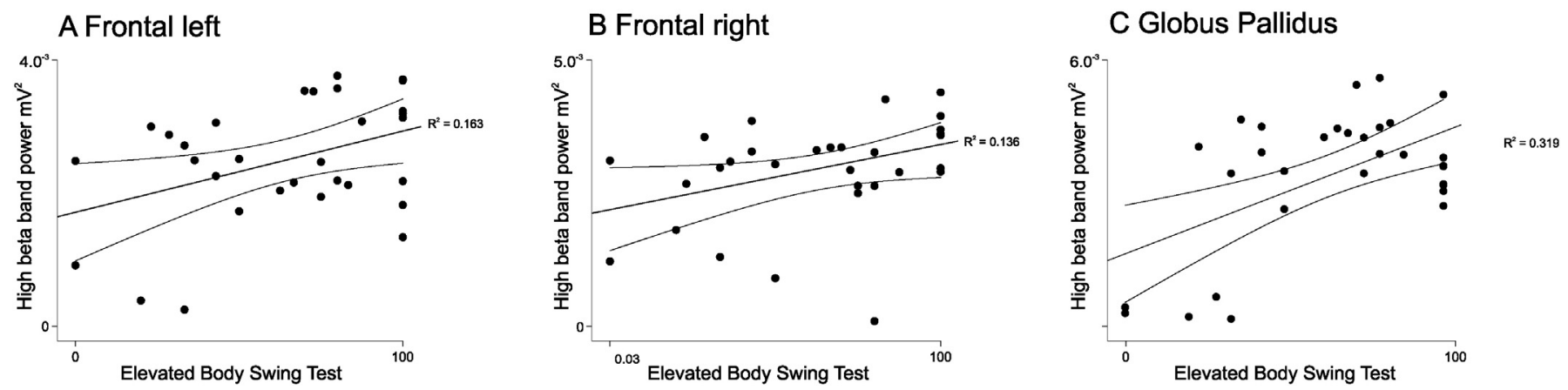

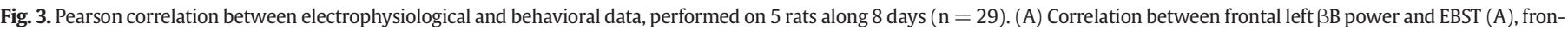

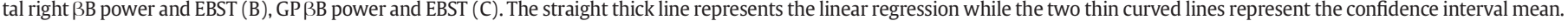

chronically-developing changes in $\beta B$ and $\gamma B$ underlie the specific involvement of these different GP neuronal sub-types.

The main findings of the present work are threefold: (i) the change of the high $\beta B$ parallels the emergence of Parkinsonian signs and was strictly and temporally associated with the severity of the reduction of TH staining; (ii) dopaminergic treatment (APO and LD) influenced the power of the two examined bands in contrasting ways, confirming their crucial role in BG pathophysiology; and (iii) dyskinetic animals showed a distinctive increase in $\gamma \mathrm{B}$ power compared with nondyskinetic animals.

The link between $\beta B$ and the development of Parkinsonism is based on the increased expression of this band within the BG of Parkinsonian animal models and PD patients, during surgery as well as during dopaminergic treatment and deep brain stimulation (Jenkinson and Brown, 2011; Kühn et al., 2006a, 2006b, 2009a, 2009b; Devos and Defebvre, 2006). We observed that high $\beta B$ matches the emergence of Parkinsonian signs detected by a non-pharmacological test; specifically, the power of high $\beta B$ had already significantly increased from the base line in the first 10 days after 6-OHDA lesioning, while there was also a right-biased swing in the EBST. Moreover, we found a positive correlation between the power of $\beta B$ in the three explored structures (mainly in the GP) and the EBST. Our results seem to contradict a previous work conducted on two MPTP-intoxicated monkeys in which synchronized oscillations in the GP emerged late, after severe Parkinsonism had developed (Leblois et al., 2007). However, in this study, the authors detected $\beta$ oscillations from two different neurons recorded extracellularly. In our study, we focused on LFP activity that originated from other sources, such as membrane potential fluctuations and synaptic potentials derived from afferent inputs (Buzsáki et al., 2012). In other words, LFP represents a suitable surrogate measure of the neuronal synchronization in the BG (Kühn et al., 2005; Weinberger et al., 2006). Of note, the depletion of striatal TH was significant in the first days after the injection, and our finding was in agreement with the rapid loss of $\mathrm{TH}+$ fibers in the striatum in the different PD rat models (Rosenblad et al., 2000; Blandini et al., 2007; Grealish et al., 2008; Ambrosi et al., 2010; Walsh et al., 2011). A detailed time course of the TH immunostaining in the rat striatum following 6-OHDA injection into the MFB demonstrated that 6-OHDA induced a loss of striatal innervation that became evident 3 days after the lesion and progressively decreased thereafter (Walsh et al., 2011). This study shows even earlier changes than those observed here; however, they used a larger amount of 6-OHDA (i.e., $12 \mu \mathrm{g}$ versus $8 \mu \mathrm{g})$. In agreement with the similar time lag between electrophysiological and histological data, we already evidenced right-biased behavior on the fifth day after the lesion.

Although there is a great deal of interest in the pathophysiological functioning of the BG in PD and the $\beta B$, in recent years, increasing evidence has demonstrated that the $\gamma \mathrm{B}$ can have as much impact as $\beta B$. Herein, we focused on the $\gamma \mathrm{B}$ comprised between 60 and $80 \mathrm{~Hz}$ since it is commonly centered on $70 \mathrm{~Hz}$ in recordings of the thalamus and the GPi (Kempf et al., 2009). We found that dopaminergic treatment accounted for a reduction of $\beta B$ and an increase of $\gamma B$. Several studies have demonstrated a suppression of $\beta B$ by dopaminergic treatment that paralleled clinical amelioration in PD patients and the reduction of $\beta B$ correlates with the degree of amelioration of the symptomology (Priori et al., 2004; Doyle et al., 2005; Kühn et al., 2006a, 2006b, 2009a, 2009b). In a recent paper by Sharott et al. (2014), a positive correlation between the percentage of STN neurons expressing $\beta$ B oscillation and the axial and rigidity signs was found; paradoxically, it was not found with bradykinesia although it is considered the main Parkinsonian feature. In contrast, in the same study, the authors demonstrated a negative correlation between $\gamma \mathrm{B}$ and bradykinesia (Sharott et al., 2014). In agreement with several human studies that found an increase of $\gamma \mathrm{B}$ after dopaminergic treatment (Alegre et al., 2005; Alonso-Frech et al., 2006; Androulidakis et al., 2007; Brown et al., 2001; Cassidy et al., 2002; Devos et al., 2006; Fogelson et al., 2005), we observed that LD treatment caused an augmentation of $\gamma \mathrm{B}$. Our findings are in agreement with some reports in humans, showing an exaggerated negative correlation between $\beta B$ and $\gamma \mathrm{B}$ in dyskinetic PD patients (Alonso-Frech et al., 2006; Fogelson et al., 2005; Silberstein et al., 2005). Similar results were observed in another hyperkinetic condition, dystonia (Chen et al., 2006). The more recent literature on the activity of the STN in PD patients, despite the obvious limitations attributable to the short time lag of acute recordings, has reinforced the notion that gamma power exerts a key physiological role in motor sequencing or during a motor task with a robust emotional contest (Huebl et al., 2014). Our observations, conducted in chronic animals, extend these previous results by the finding that $\gamma \mathrm{B}$ distinctively increased only in animals manifesting LID. This is in agreement with the observation that LID is strongly associated with more pronounced $80 \mathrm{~Hz} \mathrm{LFP} \mathrm{record-}$ ings in the primary motor cortex (Halje et al., 2012) than in the striatum, suggesting a predominantly cortical mechanism linked to the appearance of LID. Based on our data on the GP, we hypothesize a network resonance between the STN and the GP due to the hyperdirect pathway (Nambu et al., 1996; Galati et al., 2009) or even a local GP origin that is linked to DA depletion within GP. The increased $\gamma$ power that developed in dyskinetic rodents may be the network counterpart of the loss of the depotentiation at the synaptic level (Picconi et al., 2003).

One of the extreme challenges in the treatment of advanced PD patients is the difficulty in producing a stable ON-state without generating disabling LIDs. As a counterpart, studies founded on rodent models rarely define, in an unequivocal manner, the fine discrimination amongst the electrophysiological parameters that define the prokinetic ON-state versus ON-state complicated by LIDs in the same animal. Therefore, a critical point is that re-modulating the $\beta B$ or $\gamma B$ power distribution might produce a "therapeutic" state but also a LID state. Therefore, the anti-dyskinetic (mainly attributed to the GPi-DBS but also evidenced in clinical trials with STN-DBS, see Follett et al., 2010) effect of DBS may be linked to a rebalance of the prokinetic and anti-kinetic oscillation, i.e., $\gamma \mathrm{B}$ and $\beta \mathrm{B}$. 

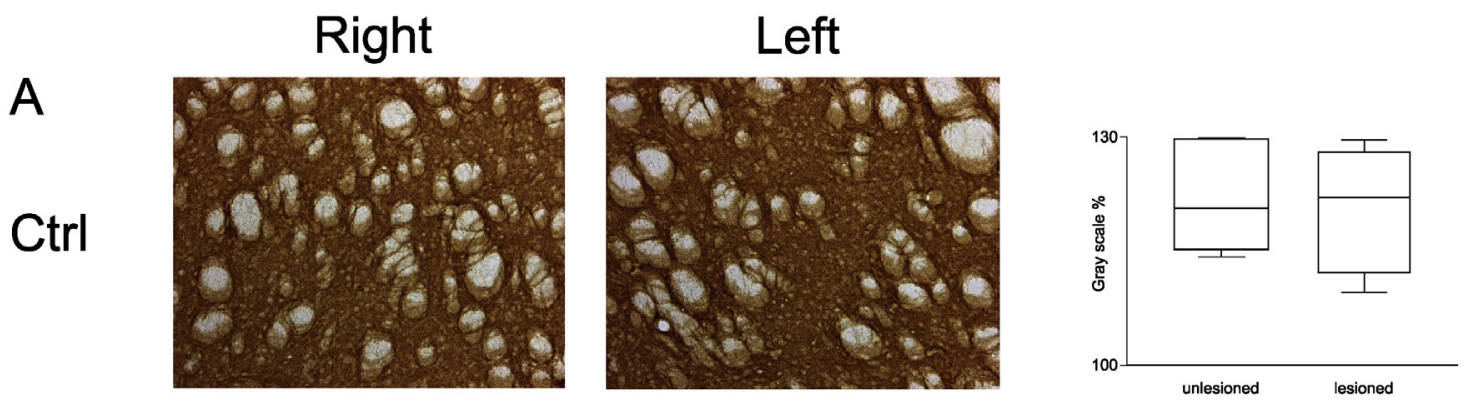

Minimum amount of

Protein 255 O.D:

Black (low values)

Maximum amount

of protein 100 O.D:
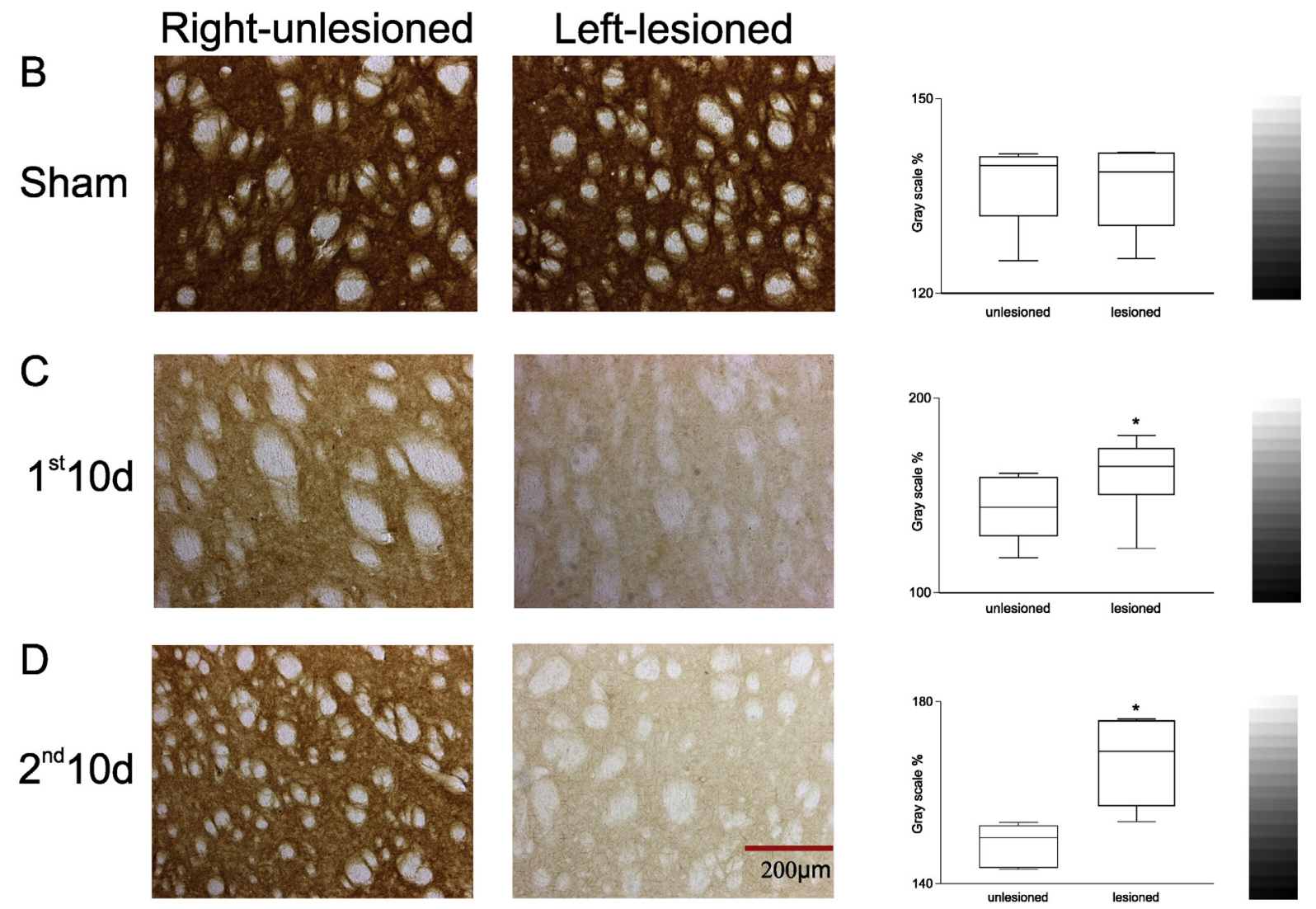

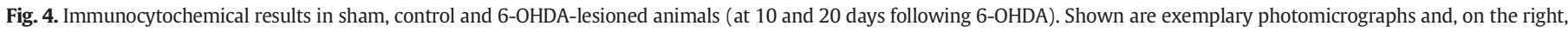

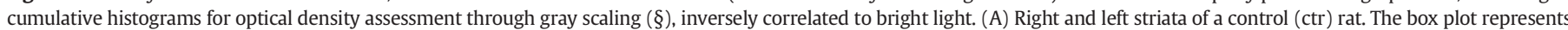

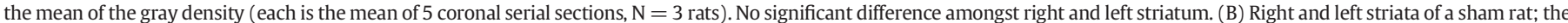

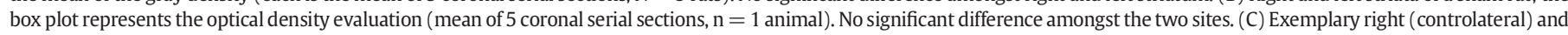

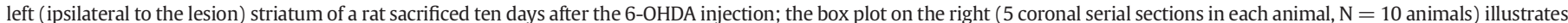

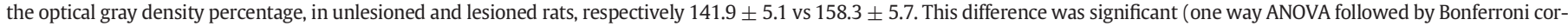

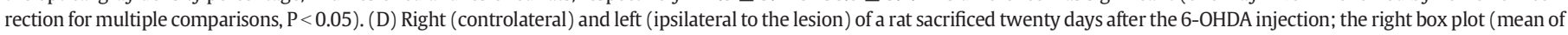

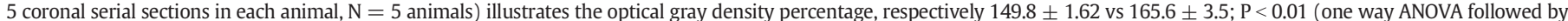
Bonferroni correction for multiple comparisons, $\mathrm{P}<0.01$ ). (For interpretation of the references to color in this figure legend, the reader is referred to the web version of this article.)

Nevertheless, it will be worth examining whether the increased $\gamma B$, which was detected here, is also detectable inside the striatum. Hernandez et al. (2013), detailed that LD may normalize the perturbed spectrum of all band dynamics minus the low- $\gamma(48 \mathrm{~Hz})$, linked by spike-field coupling to fast-spiking striatal interneurons. The latter might undergo "structural changes after DA depletion" (Hernandez et al., 2013), possibly interplaying with the GP firing mode.

In conclusion, the temporal dynamic between the emergence of $\beta \mathrm{B}$, Parkinsonian signs, and the reduction of $\mathrm{TH}$ staining attests to a strong association amongst these factors. The opposing behaviors of $\beta \mathrm{B}$ and $\gamma \mathrm{B}$ in the same recordings bear testimony to the impact of rest and movement in our observations. Our results support an intimate role for these two bands not only during a critical stage in the pathophysiology of PD, such as the development of the Parkinsonian syndrome, but more importantly, during the development of LID.

\section{Acknowledgments}

We thank Fondazione per lo studio delle malattie neurodegenerative delle persone adulte e dell'anziano for financial support to CS and SG. We thank Chiara Prosperetti for a critical reading of the manuscript. The authors are particularly grateful to Camille Mittendorf for the English revision of the manuscript. 


\section{References}

Alegre, M., Alonso-Frech, F., Rodríguez-Oroz, M.C., Guridi, J., Zamarbide, I., Valencia, M., Manrique, M., Obeso, J.A., Artieda, J., 2005. Movement-related changes in oscillatory activity in the human subthalamic nucleus: ipsilateral vs. contralateral movements. Eur. J. Neurosci. 22 (9), 2315-2324.

Alegre, M., Lopez-Azcarate, J., Obeso, I., Wilkinson, L., Rodriguez-Oroz, M.C., Valencia, M., Garcia-Garcia, D., Guridi, J., Artieda, J., Jahanshahi, M., Obeso, J.A., 2013. The subthalamic nucleus is involved in successful inhibition in the stop-signal task: a local field potential study in Parkinson's disease. Exp. Neurol. 239, 1-12.

Alonso-Frech, F., Zamarbide, I., Alegre, M., Rodríguez-Oroz, M.C., Guridi, J., Manrique, M. Valencia, M., Artieda, J., Obeso, J.A., 2006. Slow oscillatory activity and levodopainduced dyskinesias in Parkinson's disease. Brain 129 (Pt 7), 1748-1757.

Ambrosi, G., Armentero, M.T., Levandis, G., Bramanti, P., Nappi, G., Blandini, F., 2010. Effects of early and delayed treatment with an mGluR5 antagonist on motor impairment, nigrostriatal damage and neuroinflammation in a rodent model of Parkinson's disease. Brain Res. Bull. 82 (1-2), 29-38.

Androulidakis, A.G., Kühn, A.A., Chen, C.C., Blomstedt, P., Kempf, F., Kupsch, A., Schneider G.H., Doyle, L., Dowsey-Limousin, P., Hariz, M.I., Brown, P., 2007. Brain 130 (Pt 2), 457-468.

Avila, I., Parr-Brownlie, L.C., Brazhnik, E., Castañeda, E., Bergstrom, D.A., Walters, J.R., 2010. Exp. Neurol. 221 (2), 307-319.

Benhamou, L., Bronfeld, M., Bar-Gad, I., Cohen, D., 2012. Globus pallidus external segment neuron classification in freely moving rats: a comparison to primates. PLoS One 7 (9), e45421.

Blandini, F., Levandis, G., Bazzini, E., Nappi, G., Armentero, M.T., 2007. Time-course of nigrostriatal damage, basal ganglia metabolic changes and behavioural alterations following intrastriatal injection of 6-hydroxydopamine in the rat: new clues from an old model. Eur. J. Neurosci. 25 (2), 397-405.

Bolam, J.P., Hanley, J.J., Booth, P.A., Bevan, M.D., 2000. J. Anat. 196 (Pt 4), 527-542.

Borlongan, C.V., Sanberg, P.R., 1995. J. Neurosci. 15 (7 Pt 2), 5372-5378.

Brown, P., 2003. Mov. Disord. 18 (4), 357-363.

Brown, P., 2006. Bad oscillations in Parkinson's disease. J. Neural Transm. Suppl. 70 27-30.

Buzsáki, G., Anastassiou, C.A., Koch, C., 2012. The origin of extracellular fields and currents-EEG, ECoG, LFP and spikes. Nat. Rev. Neurosci. 13 (6), 407-420.

Cassidy, M., Mazzone, P., Oliviero, A., Insola, A., Tonali, P., Di Lazzaro, V., Brown, P., 2002. Movement-related changes in synchronization in the human basal ganglia. Brain 125 (Pt 6), 1235-1246.

Cenci, M.A., Lee, C.S., Bjorklund, A., 1998. L-DOPA-induced dyskinesia in the rat is associated with striatal overexpression of prodynorphin- and glutamic acid decarboxylase mRNA. Eur. J. Neurosci. 10, 2694-2706.

Chen, C.C., Kühn, A.A., Hoffmann, K.T., Kupsch, A., Schneider, G.H., Trottenberg, T. Krauss, J.K., Wöhrle, J.C., Bardinet, E., Yelnik, J., Brown, P., 2006. Neurology 66 (3), 418-420.

D'Angelo, V., Castelli, V., Saverioni, I., Cardarelli, S., Palumbo, F., Giorgi, M., Martorana, A. Bonsi, P., Pisani, A., Sancesario, G., 2015. Opposite changes of phosphodiesterase$10 \mathrm{~A}$ in striato-pallidal and striato-entopeduncular pathways of TorsinA DYT1 transgenic mice. Front. Neurol. http://dx.doi.org/10.3389/conf.fneur.2015.57.00007.

DeLong, M.R., Crutcher, M.D., Georgopoulos, A.P., 1985. J. Neurophysiol. 53 (2), $530-543$.

Devos, D., Defebvre, L., 2006. Effect of deep brain stimulation and L-DOPA on electrocortical rhythms related to movement in Parkinson's disease. Prog. Brain Res. $159,331-349$

Devos, D., Szurhaj, W., Reyns, N., Labyt, E., Houdayer, E., Bourriez, J.L., Cassim, F. Krystkowiak, P., Blond, S., Destée, A., Derambure, P., Defebvre, L., 2006. Clin. Neurophysiol. 117 (10), 2315-2327.

Doyle, L.M., Kühn, A.A., Hariz, M., Kupsch, A., Schneider, G.H., Brown, P., 2005. Eur. J. Neurosci. 21 (5), 1403-1412.

Engel, A.K., Fries, P., 2010. Curr. Opin. Neurobiol. 20 (2), 156-165.

Eusebio, A., Brown, P., 2009. Exp. Neurol. 217 (1), 1-3.

Eusebio, A., Chen, C.C., Lu, C.S., Lee, S.T., Tsai, C.H., Limousin, P., Hariz, M., Brown, P., 2007. Exp. Neurol. 209 (1), 125-130.

Flandin, P., Kimura, S., Rubenstein, J.L., 2010. The progenitor zone of the ventral medial ganglionic eminence requires Nkx2-1 to generate most of the globus pallidus but few neocortical interneurons. J. Neurosci. 30 (8), 2812-2823.

Fogelson, N., Pogosyan, A., Kühn, A.A., Kupsch, A., van Bruggen, G., Speelman, H., Tijssen, M., Quartarone, A., Insola, A., Mazzone, P., Di Lazzaro, V., Limousin, P., Brown, P., 2005. Reciprocal interactions between oscillatory activities of different frequencies in the subthalamic region of patients with Parkinson's disease. Eur. J. Neurosci. 22 (1), 257-266.

Follett, K.A., Weaver, F.M., Stern, M., Hur, K., Harris, C.L., Luo, P., Marks Jr., W.J., Rothlind, J Sagher, O., Moy, C., Pahwa, R., Burchiel, K., Hogarth, P., Lai, E.C., Duda, J.E., Holloway, K., Samii, A., Horn, S., Bronstein, J.M., Stoner, G., Starr, P.A., Simpson, R., Baltuch, G., De Salles, A., Huang, G.D., Reda, D.J., CSP 468 Study Group, 2010. Pallidal versus subthalamic deep-brain stimulation for Parkinson's disease. N. Engl. J. Med. 362 (22), 2077-2091.

Galati, S., D'angelo, V., Scarnati, E., Stanzione, P., Martorana, A., Procopio, T., Sancesario, G. Stefani, A., 2008. In vivo electrophysiology of dopamine-denervated striatum: focus on the nitric oxide/cGMP signaling pathway. Synapse 62, 409-420.

Galati, S., Stanzione, P., D'Angelo, V., Fedele, E., Marzetti, F., Sancesario, G., Procopio, T. Stefani, A., 2009. The pharmacological blockade of medial forebrain bundle induces an acute pathological synchronization of the cortico-subthalamic nucleus-globus pallidus pathway. J. Physiol. 587, 4405-4423.

Galati, S., D'Angelo, V., Olivola, E., Marzetti, F., Di Giovanni, G., Stanzione, P., Stefani, A. 2010. Acute inactivation of the medial forebrain bundle imposes oscillations in the SNr: a challenge for the 6-OHDA model? Exp. Neurol. 225 (2), 294-301.
Gittis, A.H., Berke, J.D., Bevan, M.D., Chan, CS, Mallet, N., Morrow, M.M., Schmidt, R., 2014. New roles for the external globus pallidus in basal ganglia circuits and behavior. J. Neurosci. 34, 15178-15183.

Grealish, S., Xie, L., Kelly, M., Dowd, E., 2008. Unilateral axonal or terminal injection of 6hydroxydopamine causes rapid-onset nigrostriatal degeneration and contralateral motor impairments in the rat. Brain Res. Bull. 77 (5), 312-319.

Halje, P., Tamtè, M., Richter, U., Mohammed, M., Cenci, M.A., Petersson, P.J., 2012. Levodopa-induced dyskinesia is strongly associated with resonant cortical oscillations. J. Neurosci. 21, 16541-16551

Hernandez, L.F., Kubota, Y., Hu, D., Howe, M.W., Lemaire, N., Graybiel, A.M., 2013. Selective effects of dopamine depletion and L-DOPA therapy on learning-related firing dynamics of striatal neurons. J. Neurosci. 33 (11), 4782-4795. http://dx.doi.org/10.1523/ JNEUROSCI.3746-12.2013.

Hoover, B.R., Marshall, J.F., 1999. Population characteristics of preproenkephalin mRNA-containing neurons in the globus pallidus of the rat. Neurosci. Lett. 265 (3), 199-202.

Hudson, J.L., van Horne, C.G., Strömberg, I., Brock, S., Clayton, J., Masserano, J., Hoffer, B.J., Gerhardt, G.A. 1993. Correlation of apomorphine- and amphetamine-induced turning with nigrostriatal dopamine content in unilateral 6-hydroxydopamine lesioned rats. Brain Res. 626, 167-174.

Huebl, J., Spitzer, B., Brücke, C., Schönecker, T., Kupsch, A., Alesch, F., Schneider, G.H., Kühn, A.A., 2014. Oscillatory subthalamic nucleus activity is modulated by dopamine during emotional processing in Parkinson's disease. Cortex 60, 69-81.

Jaeger, D., Gilman, S., Aldridge, J.W., 1995. Neuronal activity in the striatum and pallidum of primates related to the execution of externally cued reaching movements. Brain Res. 694 (1-2), 111-127.

Javor-Duray, B.N., Vinck, M., van der Roest, M., Mulder, A.B., Stam, C.J., Berendse, H.W., Voorn, P., 2014. Early-onset cortico-cortical synchronization in the hemiparkinsonian rat model. J. Neurophysiol. http://dx.doi.org/10.1152/jn.00690.2014.

Jenkinson, N., Brown, P., 2011. New insights into the relationship between dopamine, beta oscillations and motor function. Trends Neurosci. 34 (12), 611-618.

Kempf, F., Brücke, C., Salih, F., Trottenberg, T., Kupsch, A., Schneider, G.H., Doyle Gaynor, L.M., Hoffmann, K.T., Vesper, J., Wöhrle, J., Altenmüller, D.M., Krauss, J.K., Mazzone, P., Di Lazzaro, V., Yelnik, J., Kühn, A.A., Brown, P., 2009. Gamma activity and reactivity in human thalamic local field potentials. Eur. J. Neurosci. 29 (5), 943-953.

Kita, H., Kita, T., 2001. Number, origins, and chemical types of rat pallidostriatal projection neurons. J. Comp. Neurol. 437 (4), 438-448.

Kühn, A.A., Trottenberg, T., Kivi, A., Kupsch, A., Schneider, G.H., Brown, P., 2005. The relationship between local field potential and neuronal discharge in the subthalamic nucleus of patients with Parkinson's disease. Exp. Neurol. 194 (1), 212-220.

Kühn, A.A., Kupsch, A., Schneider, G.H., Brown, P., 2006a. Reduction in subthalamic 8$35 \mathrm{~Hz}$ oscillatory activity correlates with clinical improvement in Parkinson's disease. Eur. J. Neurosci. 23 (7), 1956-1960.

Kühn, A.A., Doyle, L., Pogosyan, A., Yarrow, K., Kupsch, A., Schneider, G.H., Hariz, M.I., Trottenberg, T., Brown, P., 2006b. Modulation of beta oscillations in the subthalamic area during motor imagery in Parkinson's disease. Brain 129 (Pt 3), 695-706.

Kühn, A.A., Fogelson, N., Limousin, P.D., Hariz, M.I., Kupsch, A., Brown, P., 2009a. Frequency-specific effects of stimulation of the subthalamic area in treated Parkinson's disease patients. Neuroreport 20 (11), 975-978.

Kühn, A.A., Tsui, A., Aziz, T., Ray, N., Brücke, C., Kupsch, A., Schneider, G.H., Brown, P., 2009b. Pathological synchronisation in the subthalamic nucleus of patients with Parkinson's disease relates to both bradykinesia and rigidity. Exp. Neurol. 215 (2), 380-387.

Leblois, A., Meissner, W., Bioulac, B., Gross, C.E., Hansel, D., Boraud, T., 2007. Late emergence of synchronized oscillatory activity in the pallidum during progressive Parkinsonism. Eur. J. Neurosci. 26 (6), 1701-1713.

Lehmkuhle, M.J., Bhangoo, S.S., Kipke, D.R., 2009. The electrocorticogram signal can be modulated with deep brain stimulation of the subthalamic nucleus in the hemiparkinsonian rat. J. Neurophysiol. 102 (3), 1811-1820.

Levy, R., Lang, A.E., Dostrovsky, J.O., Pahapill, P., Romas, J., Saint-Cyr, J., Hutchison, W.D., Lozano, A.M. 2001. Lidocaine and muscimol microinjections in subthalamic nucleus reverse parkinsonian symptoms. Brain 124 (Pt 10), 2105-2118.

Litvak, V., Eusebio, A., Jha, A., Oostenveld, R., Barnes, G., Foltynie, T., Limousin, P., Zrinzo, L., Hariz, M.I., Friston, K., Brown, P., 2012. Movement-related changes in local and longrange synchronization in Parkinson's disease revealed by simultaneous magnetoencephalography and intracranial recordings. J. Neurosci. 32 (31), 10541-10553.

Mallet, N., Pogosyan, A., Márton, L.F., Bolam, J.P., Brown, P., Magill, P.J., 2008. Parkinsonian beta oscillations in the external globus pallidus and their relationship with subthalamic nucleus activity. J. Neurosci. 24 (52), 14245-14258,

Mallet, N., Micklem, B.R., Henny, P., Brown, M.T., Williams, C., Bolam, J.P., Nakamura, K.C., Magill, P.J., 2012. Dichotomous organization of the external globus pallidus. Neuron 74 (6), 1075-1086.

Mastro, K.J., Bouchard, R.S., Holt, H.A., Gittis, A.H., 2014. Transgenic mouse lines subdivide external segment of the globus pallidus (GPe) neurons and reveal distinct GPe output pathways. J. Neurosci. 34 (6), 2087-2099.

Morgan, S., Huston, J.P., 1990. The interhemispheric projection from the substantia nigra to the caudate-putamen as depicted by the anterograde transport of [3H]leucine. Behav. Brain Res. 38 (2), 155-162.

Nambu, A., Llinaś, R., 1994. Electrophysiology of globus pallidus neurons in vitro. J. Neurophysiol. 72 (3), 1127-1139.

Nambu, A., Takada, M., Inase, M., Tokuno, H., 1996. Dual somatotopical representations in the primate subthalamic nucleus: evidence for ordered but reversed body-map transformations from the primary motor cortex and the supplementary motor area. J. Neurosci. 16 (8), 2671-2683 (15).

Nini, A., Feingold, A., Slovin, H., Bergman, H., 1995. Neurons in the globus pallidus do not show correlated activity in the normal monkey, but phase-locked oscillations appear in the MPTP model of Parkinsonism. J. Neurophysiol. 74 (4), 1800-1805. 
Nóbrega-Pereira, S., Gelman, D., Bartolini, G., Pla, R., Pierani, A., Marín, O., 2010. Origin and molecular specification of globus pallidus neurons. J. Neurosci. 30 (8), 2824-2834.

Paxinos, G., Franklin, K.B.J., 2004. The mouse brain in stereotaxic coordinates. Compact, 2nd ed. Elsevier Academic Press, Amsterdam, Boston $1 \mathrm{p}$.

Picconi, B., Centonze, D., Håkansson, K., Bernardi, G., Greengard, P., Fisone, G., Cenci, M.A., Calabresi, P., 2003. Loss of bidirectional striatal synaptic plasticity in L-DOPA-induced dyskinesia. Nat. Neurosci. 6 (5), 501-506 (May).

Pierucci, M., Di Matteo, V., Benigno, A., Crescimanno, G., Esposito, E., Di Giovanni, G., 2009. The unilateral nigral lesion induces dramatic bilateral modification on rat brain monoamine neurochemistry. Ann. N. Y. Acad. Sci. 1155, 316-323.

Priori, A., Foffani, G., Pesenti, A., Tamma, F., Bianchi, A.M., Pellegrini, M., Locatelli, M., Moxon, K.A., Villani, R.M., 2004. Rhythm-specific pharmacological modulation of subthalamic activity in Parkinson's disease. Exp. Neurol. 189 (2), 369-379.

Rosenblad, C., Grønborg, M., Hansen, C., Blom, N., Meyer, M., Johansen, J., Dagø, L., Kirik, D., Patel, U.A., Lundberg, C., Trono, D., Björklund, A., Johansen, T.E., 2000. In vivo protection of nigral dopamine neurons by lentiviral gene transfer of the novel GDNF-family member neublastin/artemin. Mol. Cell. Neurosci. 15 (2), 199-214.

Sancesario, G., Giorgi, M., D'Angelo, V., Modica, A., Martorana, A., Morello, M., Bengtson, C.P., Bernardi, G., 2004. Down-regulation of nitrergic transmission in the rat striatum after chronic nigrostriatal deafferentation. Eur. J. Neurosci. 20 (4), 989-1000.

Schwarting, R.K., Huston, J.P., 1996. The unilateral 6-hydroxydopamine lesion model in behavioral brain research. Analysis of functional deficits, recovery and treatments. Prog. Neurobiol. 50, 275-331.

Sharott, A., Magill, P.J., Harnack, D., Kupsch, A., Meissner, W., Brown, P., 2005. Dopamine depletion increases the power and coherence of beta-oscillations in the cerebral cortex and subthalamic nucleus of the awake rat. Eur. J. Neurosci. 21 (5), 1413-1422.
Sharott, A., Gulberti, A., Zittel, S., Tudor Jones, A.A., Fickel, U., Münchau, A., Köppen, J.A Gerloff, C., Westphal, M., Buhmann, C., Hamel, W., Engel, A.K., Moll, C.K., 2014. Activity parameters of subthalamic nucleus neurons selectively predict motor symptom severity in Parkinson's disease. J. Neurosci. 34 (18), 6273-6285.

Silberstein, P., Oliviero, A., Di Lazzaro, V., Insola, A., Mazzone, P., Brown, P., 2005. Oscillatory pallidal local field potential activity inversely correlates with limb dyskinesias in Parkinson's disease. Exp. Neurol. 194 (2), 523-529.

Steigerwald, F., Pötter, M., Herzog, J., Pinsker, M., Kopper, F., Mehdorn, H., Deuschl, G. Volkmann, J., 2008. Neuronal activity of the human subthalamic nucleus in the parkinsonian and nonparkinsonian state. J. Neurophysiol. 100 (5), 2515-2524.

Timmermann, L., Wojtecki, L., Gross, J., Lehrke, R., Voges, J., Maarouf, M., Treuer, H., Sturm, V., Schnitzler, A., 2004. Ten-hertz stimulation of subthalamic nucleus deteriorates motor symptoms in Parkinson's disease. Mov. Disord. 19 (11), 1328-1333.

Turner, R.S., Anderson, M.E., 1997. Pallidal discharge related to the kinematics of reaching movements in two dimensions. J. Neurophysiol. 77 (3), 1051-1074.

Vorobyov, V., Sengpiel, F., 2008. Apomorphine-induced differences in cortical and striatal EEG and their glutamatergic mediation in 6-hydroxydopamine-treated rats. Exp. Brain Res. 191 (3), 277-287.

Walsh, S., Finn, D.P., Dowd, E., 2011. Time-course of nigrostriatal neurodegeneration and neuroinflammation in the 6-hydroxydopamine-induced axonal and terminal lesion models of Parkinson's disease in the rat. Neuroscience 175, 251-261.

Weinberger, M., Mahant, N., Hutchison, W.D., Lozano, A.M., Moro, E., Hodaie, M., Lang A.E., Dostrovsky, J.O., 2006. Beta oscillatory activity in the subthalamic nucleus and its relation to dopaminergic response in Parkinson's disease. 96 (6), 3248-3256. 